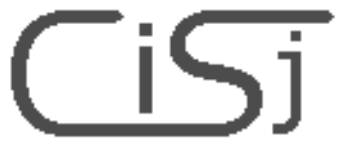

\title{
NUMERICAL MODELING OF MOMENT METHOD FOR ANTENNA SIMULATION
}

\author{
René Hart'anský, Dušan Maga, Peter Široký \\ Alexander Dubcek university of Trencin, Faculty of mechatronics, Dpt. of Mechatronics, Studentska 1,911 50 Trencin, \\ Slovak Republic \\ E-mail: rene@yhman.tnuni.sk,maga@yhman.tnuni.sk, siroky@tnuni.sk
}

\begin{abstract}
Paper includes accuracy problems of numerical computing of wire antennas characteristics, specially resistively loaded dipoles - antennas with varying inner impedance. One may find here the modification of Pocklington's equation (numerical computation of resistive dipole) to the form, which allows us to decrease the number of dipole segmentation elements.
\end{abstract}

Keywords: computing, numerical methods, antenna modelling, current distribution, method of moment.

\section{INTRODUCTION}

Method of moment (MoM) is numerical method for wire antenna analysis which is the most frequently used to find the solution of internal and external antenna task of given antenna type. If the MoM is based upon Hallen's integral equation (without source function), the task solution is relatively simple. In this reason it may be used for current distribution analysis. But if the antenna is made from resistive material or its internal resistance is varying with position on antenna arms, the problem of numerical computing becomes more complicated. Hallen's integral equation can not be used. It must be replaced by Pocklington's one, on the right side of which not only source function is present, but also the multiplication function of internal wire impedance and the unknown current. Typical example of this antenna type is resistively loaded dipole with travelling wave. It is often used as electric field sensor in electromagnetic compatibility area for immunity testing [1], [2] and [3]. As it could be found in [3], the non perfection antenna simulation was very time and (CPU time) consuming. For this reasons it was desired to find out such way of Pocklington's equation solution, which could remove this shortages. As written in following text the solution was found by the connection of numerical and analytical integration of separate parts of the equation and by utilising the properties of impedance matrix.

\section{PROBLEM FORMULATION}

On the base of [1], in which the resistive dipole is described in more details, the figure 1 was prepared. The antenna consists of a cylinder of length $2 h$ and its wire diameter is $2 a$. It has an internal impedance $\mathrm{Z}^{\mathrm{i}}(\mathrm{z})$, due to continuous complex impedance loading, and carries an axial current $\mathrm{I}_{\mathrm{z}}(\mathrm{z})$, which is assumed to be uniformly around the periphery of the cylinder since the radius is much less than the wavelength, $\lambda$. According to [2] one can suppose, that the current is flowing only in $z$ axis direction and it is equal to zero in the point $z=h$. The dipole is made from non perfection conductors material, so that its internal impedance satisfies the equation (3). The dipole is fed in the point given by $z=0$ by voltage $U_{0}$. On the base of this prepositions the axial component of vector potential must satisfy one-dimensional wave equation:

$\left(\frac{\partial^{2}}{\partial z^{2}}+k^{2}\right) A_{z}(z)=\frac{j k^{2}}{\omega}\left[Z^{i}(z) I_{z}(z)-U_{0} \delta(z)\right]$

where $A_{z}(z)$ is vector potential 


$$
A_{z}(z)=\frac{\mu}{4 \pi} \int_{-h}^{h} I_{z}\left(z^{\prime}\right) \frac{e^{-j k \sqrt{\left(z-z^{\prime}\right)^{2}+a^{2}}}}{\sqrt{\left(z-z^{\prime}\right)^{2}+a^{2}}}
$$

while

$2 h$ is physical length of antenna [m]

$k$ is wave number $\left[\mathrm{rad} . \mathrm{m}^{-1}\right.$ ]

$\omega$ is angle frequency $\left[\mathrm{rad} . \mathrm{s}^{-1}\right]$

$\mu O$ is vacuum permeability $\left[\mathrm{H} . \mathrm{m}^{-1}\right]$

$\delta(z)$ is Dirac function [1]

The internal dipole arm wire impedance $Z^{\mathrm{i}}(\mathrm{z})$ in (1) is given by [1]

$Z^{i}(z)=\frac{\Psi}{h-|z|}$

where $\Psi$ is the constant dependent on dipole dimensions and conductivity of dipole materials.

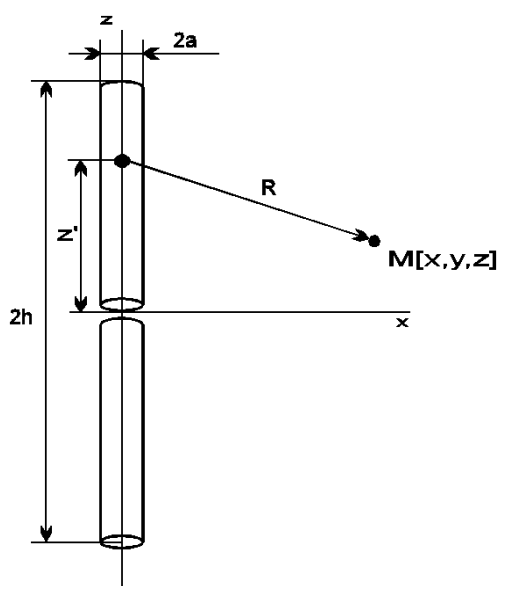

Fig. 1 - The geometry of resistive loaded dipole

\section{STANDARD NUMERICAL MODELLING}

Method of moment, as was already written, is advantageous for integral equation solution. The basis of this method is in division of integral equation into the system of algebraic equations, which are simply soluble. In praxis it means to divide the dipole into $N$ segments and to express the current flowing in each segment. After some modification the equation (1) must obtain the following form

$\sum I_{n} \cdot Z_{n m}=U_{m}$ where $I_{n}$ is the vector of unknown currents, $U_{m}$ is the vector of dipole feeding voltages, which contains only voltage $\mathrm{U}_{0}$ at the point of dipole feeding, i. e. for N/2-th segment and zeros for other segments. $Z_{\mathrm{nm}}$ is impedance matrix calculated by following way: by means of figure 1 the position of vector oriented from the point $\mathrm{N}$ on the dipole to the point of observation $\mathrm{M}$ is defined. Its length is equal to

$$
R_{z z^{\prime}}=\sqrt{\left(z-z^{\prime}\right)^{2}+a^{2}}
$$

The derivation in (1) must be put under the integral and then the integrand has the form

$$
\Xi_{y y^{\prime}}=\frac{d}{d z} G_{z z^{\prime}}+k^{2} G_{z z^{\prime}}
$$

where

$$
G_{z z^{\prime}}=\frac{e^{-j k R_{z z^{\prime}}}}{4 \pi R_{z z^{\prime}}}
$$

On the basis of preceding equation the impedance $\mathrm{Z}_{\mathrm{nm}}$ is calculated as:

$$
Z_{n m}=\frac{1}{j 2 \pi f \varepsilon_{0}} \int_{z_{n-1 / 2}}^{z_{n+1 / 2}} \Xi_{z_{n m^{\prime}}} d z+Z^{i}\left(z_{m}\right)\left(z_{m+1 / 2}-z_{m-1 / 2}\right)
$$

Current distribution calculation according to (4) using (8) is a time consuming one, while it must perform n.m numerical derivations and integration. Even the suitable simulation results will come only after increasing the number of segments to 600 or more (So the matrix of 600.600 complex numbers will be obtained, which requires a corresponding hardware aids) [3].

\section{ADV ANCED NUMERICAL MODELLING}

Since the solution of equation (4) and (8) is very difficult to realise on obvious hardware means (PC computer), such a way of the equation (1) solution has to be found, that reaches satisfactory results with minimum number of segments and numerical derivations and integration. One way how to solve this problem is the division of the equation (4) into 
two separate parts. This seems to be a suitable solution. One part will contain only the impedance dependent upon the current distribution (the first part of the equation (8)) and the second only those impedance, which depend on the shape and the material, from which the dipole is made (the second part of the equation (8))

$$
\mathbf{Z}_{\mathrm{nm}}=\mathbf{Z}_{\mathrm{nm}}^{\prime}+\mathbf{Z}_{\mathrm{nm}}^{\mathrm{i}}
$$

Utilising the features of moment method applied for Pocklington's equation for the matrix $Z_{n m}^{\prime}$ and utilising the fact, that for impedance calculation the length of the position vector is needed and not its orientation, the equation (10) can be written. For example the length of vector $R_{z z^{\prime}}$ from point 1 to point 1 is the same as the length from any point to the same point, so all diagonal elements are the same. Also in our case the length of vector connecting neighbouring segments are the same. Based on previous statement, the following equation can be presented:

$$
\mathbf{Z}_{\mathrm{nm}}^{\prime}=\left(\begin{array}{cccccc}
Z_{1}^{\prime} & Z_{2}^{\prime} & Z_{3}^{\prime} & Z_{4}^{\prime} & Z_{5}^{\prime} & \ldots \\
Z_{2}^{\prime} & Z_{1}^{\prime} & Z_{2}^{\prime} & Z_{3}^{\prime} & Z_{4}^{\prime} & \ldots \\
Z_{3}^{\prime} & Z_{2}^{\prime} & Z_{1}^{\prime} & Z_{2}^{\prime} & Z_{3}^{\prime} & \ldots \\
\vdots & \vdots & \vdots & \vdots & \vdots & \ddots
\end{array}\right)
$$

The fact, that it is not necessary to solve $m . n$ numerical integration and derivations, follows from equation (10). But it is needed only to calculate the first matrix row and all remaining rows will are only the combinations of the elements of the first row. To increase the precision of internal impedance estimation of each dipole segment, it is required to modify the calculation of $\mathrm{Z}_{\mathrm{mn}}^{\mathrm{i}}$ according to following formula

$$
Z_{n m}^{i}=\int_{m-1 / 2}^{m+1 / 2} \frac{\Psi}{h-|z|} d z
$$

From (11) one can obtain:

$$
Z_{n m}^{i}= \begin{cases}\Psi\left(\ln \left(z_{m-1 / 2}-h\right)-\ln \left(z_{m+1 / 2}+h\right)\right) & z>0 \\ \Psi\left(\ln \left(h+z_{m-1 / 2}\right)-\ln \left(h+z_{m+1 / 2}\right)\right) & z<0\end{cases}
$$

On the basis of last two equations one can create the matrix of internal impedance

$$
\mathbf{z}_{\mathrm{nm}}^{\mathrm{i}}=\left(\begin{array}{cccc}
Z_{1} & Z_{1} & Z_{1} & \ldots \\
Z_{2} & Z_{2} & Z_{2} & \ldots \\
Z_{3} & Z_{3} & Z_{3} & \ldots \\
\vdots & \vdots & \vdots & \ddots
\end{array}\right)
$$

When summarised equations (10) and (13), the classic method of moments is obtained. However, in this case it is necessary to solve only the system of linear equations according to (4).

\section{RESULT OF THE BOTH METHODS}

On the basis of the analysis made in chapters 2 and 3 the programs solving the given problem were created in the Mathematica environment. This software tool is designed to solve mathematical problems, which gives to the operator an user friendly access to effective algorithm writing of particular equations required for calculations of current distribution and other parameters. The task can be divided into several functions, which solve particular problems and by means of them one can calculate the problem solution. This feature allows us to change input parameters of simulation (dipole dimensions, material parameters, number of segments, required characteristics) very simply. The effective antenna height can be also calculated according to formula

$$
h_{e}(f)=\frac{1}{I_{z}(0)} \sum_{m=1}^{M} I_{z}\left(z_{m}\right)\left(z_{m+1 / 2}-z_{m-1 / 2}\right)
$$

To check the behaviour of proposed method the current distribution along resistive dipole with dimensions of $2 \mathrm{~h}=30 \mathrm{~cm}$ and $\mathrm{a}=1 \mathrm{~mm}$ has been calculated. Numerical calculation was made for dipole divided into 121 segments. Then the real part of effective antenna height was calculated. The resulting frequency dependence was compared to analytical solution given in literature [3]. The comparison can be seen in figure 2, which shows very good agreement of both results. 


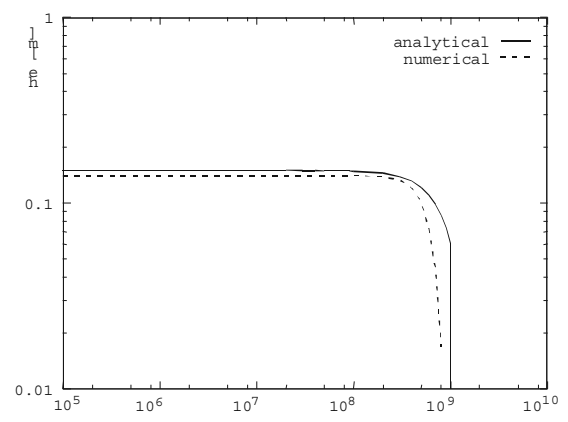

Fig. 2 - The effective dipole height - real component

\section{CONCLUSION}

The paper describes new modification of resistive dipoles solution by method of moments. Proposed method can be applied also for standard wire dipoles, which are made from real metallic material with finite conductivity. The next contribution of the paper is the fact, that the given method allows us to use cheap computer aids for solving complicated antenna problems in stead of more powerful computers. This needs only the modification of mathematical formulation of solved problem. Time required for calculations according to proposed method is less than 0.1 of the previous one described in [3]. This gives us an opportunity to use classical PC for antenna problem solving.

\section{REFERENCES}

[1] Kanda, M.: Standard probes for electromagnetic field measurement, IEEE Trens. Antennas Propagat., vol. 41, pp 1349-1364, October 1993

[2] Kanda, M.: Time-domain sensors and radiators, in Time Domain Measurements is Electromagnetic, E. K. Miller, ed. New York: Van Nostrand, 1986

[3] Johnk, C., T., A.: Engineering electromagnetic field and wave, New York, John Wiley \& Sons, 1988

[4] Skala, B.: Mereni vykonu $v 3 f$ obvodech a prenos namerenych dat do PC. In Pinker, J. (ed.): Aplikovaná elektronika 99. Západočeská univerzita v Plzni: 165-168. Plzeň 1999.

[5] Hrabovcová, V., Rafajdus, P., Janoušek, L.: Elektrické stroje v teórii a príkladoch, University of Žilina, 1998

[6] Bittera, M., Valúch, D.: Modelling of absorber influence on properties of EMC test chamber using FEM. The 4-th Scientific Conference on Electrical Engineering \& Information Technology for PhD. students, ELITECH 2001, Bratislava, 29 November 2001, pp.132-134.

[7] Hajach, P., Hartanský, R.: Solution of Resistive Loaded Dipoles by Hallen Method and by Moment Method, 10th Internat. Scientific Conference Radioelektronika 2000, Bratislava, Slovak Republic 12 - 13 September 2000, pp. IV-62 - IV-64
René HARŤANSKÝ (MSc., PhD.) was born in Banská Bystrica on May 13th, 1969. He received the MSc. degree in 1992 and then PhD. degree in electrical engineering from the Faculty of Electrical Engineering of the Slovak Technical University (FEE STU). He is currently the Assistant professor at the Department of Mechatronics TnU of Alexander Dubcek. His research interest are the computer modelling EMC phenomena, antennas and propagation.

Dušan MAGA (assoc. Prof., MSc., PhD., MIEE) was born in Nitra on 30. 7. 1968. He has received his MSc. (1991) and PhD. (1998) degree in field of power engineering at Faculty of Electrical Engineering, Slovak Technical University, Bratislava. He received the assoc. Prof. degree in Technical University of Zilina. Recently he is the head of department of Mechatronic Systems at Alexander Dubcek University in Trencin. His research interests are FEM, CAD-CAM-CAE, electrical machines.

Peter ŠIROKÝ (MSc.) was born in Trenčin on 26.03.1973. He has received his MSc. (1997) on Faculty of Information and Security Systems in University of Žilina. Recently he is head of power laboratories of Alexander Dubček University of Trenčín. His research interests are Fault tolerance systems, electric system design, electrical machines. 